\title{
ANALISIS KUALITAS LAYANAN WEBSITE SIKMB MENGGUNAKAN METODE WEBQUAL 4.0 (STUDI PADA BP BATAM)
}

\author{
Tukino \\ Universitas Putera Batam \\ Jalan R. Soeprapto, Muka Kuning - Batam \\ mas.kino@gmail.com
}

\begin{abstract}
The growth of ICT so rapidly make the website as an integral part of an agency in terms of services for users. Service of a website need to be measured to determine the level of user satisfaction and obtain feedback. In this study, the quality of the website SIKMB on BP Batam is measured by using the method of WebQual 4.0. WebQual is an instrument that assesses the quality of a website according to the end-user perspective. This study conducted an analysis of the website SIKMB on BP Batam by using Descriptive method with the number of respondents as many as 151 with a margin of error of 5\% with a confidence level of $95 \%$. From the results it can be concluded that: (1). The aspect of Usability on the website SIKMB in BP Batam has been good; (2). Aspects of the Quality of the Information on the website SIKMB in BP Batam is already good; (3). Aspects of Quality of Interaction on the website SIKMB in BP Batam has been good; (4). However, the overall value of the quality of the website SIKMB to a dimension of the Ease of the User, the Quality of Information, and the Quality of Interaction on the website SIKMB in BP Batam is located in a good quality.
\end{abstract}

Keywords: WebQual, Usability, Quality of Information, Quality of Interaction.

\begin{abstract}
Abstrak
Pertumbuhan TIKyang demikian pesat menjadikan website sebagai bagian yang tidak terpisahkan dari sebuah instansi dalam hal layanan bagi pengguna. Layanan suatu website perlu diukur untuk mengetahui tingkat kepuasan pengguna dan memperoleh umpan balik. Dalam penelitian ini, kualitas website SIKMB pada BP Batam diukur dengan menggunakan metode WebQual 4.0. WebQual merupakan instrumen yang menilai kualitas suatu website menurut perspektif pengguna akhir. Penelitian ini melakukan analisis website SIKMB pada BP Batam dengan menggunakan metode Deskriptif dengan jumlah reponden sebanyak 151 dengan margin error sebesar 5\% dengan tingkat kepercayaan 95\%. Dari hasil penelitian dapat disimpulkan bahwa: (1). Aspek Kemudahan Penggunaan pada website SIKMB di BP Batam sudah baik; (2). Aspek Kualitas Informasi pada website SIKMB di BP Batam sudah baik; (3). Aspek Kualitas Interaksi pada website SIKMB di BP Batam sudah baik; (4). Namun keseluruhan nilai kualitas website SIKMB terhadap dimensi Kemudahan Pengguna, Kualitas Informasi, dan Kualitas Interaksi pada website SIKMB di BP Batam berada dalam kualitas yang baik.
\end{abstract}

Kata kunci: WebQual, Kemudahan Penggunaan, Kualitas Informasi, Kualitas Interaksi. 


\section{PENDAHULUAN}

Perkembangan teknologi dan informasi dalam beberapa dekade terakhir ini berlangsung begitu pesat yang telah memberikan perubahan dalam segala segi seperti segi hubungan sosial, budaya dan ekonomi dunia. Perusahaan besar, menengah dan kecil dalam perkembangannya cenderung sangat dipengaruhi oleh pengimplementasian teknologi informasi dan sumber daya manusia yang baik. Salah satu contoh yang bisa kita lihat yaitu pada Kota Batam. Dimana perubahannya dapat dilihat sejak awal pembangunan pada tahun 1968 hingga pada masa sekarang ini. Kota Batam memiliki potensi maupun kemampuan aktual untuk memberi kontribusi terhadap kemajuan ekonomi Nasional maupun daerah Pulau Batam dan sekitarnya. Posisinya yang sangat dekat dengan negara industri Singapura, membuat kawasan ini sangat berpotensi untuk menampung luapan ekonomi dari negara Singapura yang sudah tergolong maju. Perkembangan dunia internet saat ini sangatlah pesat, hal ini di dukung dengan perkembangan infrastruktur teknologi.

BP Batam, melalui unit Pusat Pengolahan Data dan Sistem Informasi (PDSI), pada tahun 2014 telah melakukan sosialisasi kurang lebih 250 pengusaha untuk melakukan perizinan secara online melalui aplikasi SIKMB (Sistem Informasi Keluar Masuk Barang). Sampai saat ini perizinan yang sudah bisa dilakukan melalui online adalah permohonan izin usaha impor dan permohonan untuk mendapatkan pengakuan sebagai importir (Importir Terbatas atau IT, Importir Produsen atau IP dan Importir Terbatas-Produk Tertentu atau IT-PT).

Permohonan secara online dapat dilakukan melalui internet dengan mengakses pada website http://SIKMB.bpbatam.goid. Situs SIKMB dalam pengelolaannya bersifat tertutup dalam arti pengusaha yang bisa mengakses adalah pengusaha yang sudah mendapatkan hak akses dan perjanjian hak akses antara BP Batam dan pihak pengusaha. Saat ini pengusaha yang sudah mendapatkan hak akses dan izin usaha impor secara elektronik adalah sebanyak 252 perusahaan. Pengunaan perizinan secara online melalui Website http://SIKMB.bpbatam.go.id akan dilakukan secara bertahap terhadap para pengusaha di FTZ Batam, dan diharapkan pada akhir tahun 2015 semua pengusaha bisa melakukan perizinan untuk kegiatan impor melalui sistem elektronik online [1].

Perizinan yang dikeluarkan oleh sistem SIKMB adalah Izin Usaha impor dan Pengakuan Impor (IT, IP dan IT-PT), yang mana perizinannya juga bisa dilihat di halaman masing-masing user. Kedua Perizinan tersebut masih bersifat hard copy dengan tanda tangan basah, sedangkan untuk persetujuan pemasukan barang akan menggunakan tanda tangan elektronik yang juga terhubung dengan Bea Cukai Batam. Pihak Kantor Bea Cukai Batam dapat mengakses semua perizinan yang telah dikeluarkan oleh BP Batam dengan mengakses aplikasi online SIKMB [1].

Pengusaha akan dipermudah dengan Penggunaan aplikasi SIKMB secara online, untuk persetujuan pemasukan barang bisa dilakukan secara online dan persetujuannya juga langsung diperoleh secara online pada masing-masing user melalui komputer, sehingga tidak perlu lagi mendatangi kantor BP Batam lagi. Perizinannya juga bisa dilihat di komputer dan bisa diprint perizinannya. Direktorat Lalu Lintas Barang BP Batam akan terus berupaya untuk meningkatkan pelayanan perizinan di bidang impor dan ekspor. Perizinan tersebut merupakan pelimpahan 
kewenangan yang dinerikan oleh pemerintah pusat, dalam hal ini adalah Kementrian Perdagangan untuk mengeluarkan perizinan yang berkaitan dengan perdagangan luar negeri [1].

Saat ini BP Batam sudah menerapkan sistem online, namun masih banyak kendala yang di hadapi baik oleh BP Batam selaku Institusi Resmi yang mengeluarkan perizinan dan juga para pengusaha yang menggunakan aplikasi SIKMB. Pada aplikasi SIKMB yang lama hanya beberapa saja perizinan yang dapat dilakukan secara online, namun dengan adanya perbaikan SIKMB, maka perizinan akan dapat dilakukan secara online semua.

BP Batam bersama dengan Bea Cukai, Direktorat IKC telah melakukan koordinasi agar aplikasi SIKMB dapat dilakukan secara integrasi dengan sistem nasional single window yang sudah berjalan di Bea dan Cukai Jakarta. Diharapkan dalam waktu dekat ini integrasi dan pertukaran data dengan Bea dan Cukai dapat terealisasi, sehingga perusahaan yang sudah mendapatkan izin tidak diperlukan lagi endorse ke BP Batam. BP Batam dalam hal ini Direktorat Lalu Lintas Barang berupaya terus untuk memperbaiki intergritas SDM, masukan dari para pengusaha serta pengalaman praktis selama menjalankan aplikasi online merupakan dasar bagi perbaikan sistem. Tahap demi tahap akan dilakukan perbaikan baik dari sisi hardware dan software [1].

Diharapkan para pengusaha juga ikut berpartisipasi dalam mensukseskan Penggunaan sistem online, karena hanya dengan sistem ini proses perizinan dapat berjalan secara transparan, jelas dan akutabilitas. Kecepatan proses perizinan menjadi jauh lebih cepat dari proses manual. Keuntungan yang diperoleh jika badan usaha bisa memanfaatkan internet salah satunya ialah akan lebih mudah memberikan informasi kepada Pengguna. Hal tersebut merupakan suatu strategi bisnis yang dapat diberikan secara multimedia yang akan membantu meningkatkan mutu dari kualitas pelayanan, kenyamanan, efektifitas dan efisiensi informasi yang diberikan terhadap konsumen.

Salah satu fasilitas kecanggihan internet yang banyak digunakan oleh pelaku bisnis sebagai sarana untuk mempromosikan produk atau jasanya, yakni melalui website. Dengan memiliki website berarti kita sama saja mempunyai karyawan yang mempromosikan produk kita selama 24 jam sehari dan 7 hari seminggu. Artinya website akan memberikan informasi kepada calon pembeli selama 24 jam non stop. Itu sebabnya, promosi produk atau jasa dalam website menjadi sangat penting. Selain efektifitas penjualan, sebagai tujuan membuat website, pada prinsipnya tujuan promosi website sangat terkait dengan tujuan dibangunnya website yang bersangkutan [2].

Kualitas website sangat berpengaruh terhadap tingkat kepuasan Penggunanya itu sendiri. Semakin tinggi kualitas suatu web, maka akan semakin banyak Pengguna yang mengakses web tersebut. Hal ini sesuai dengan penelitian [3] dengan menggunakan konsep metode pengukuran suatu website mengunakan metode webqual dengan indikator kualitas informasi web, kualitas desain web serta kualitas Penggunaan pada e-library menghasilkan bahwa kualitas informasi web, kualitas desain web serta kualitas Penggunaan mempengaruhi tingkat kepuasan Pengguna. 
Pada dasarnya tercapainya kualitas website yang sempurna akan mendorong terciptanya kepuasan pelanggan, karena kualitas website merupakan sarana untuk mewujudkan kepuasan Pengguna dalam mengakses website. Kualitas website tentu dapat diwujudkan dengan menampilkan website yang sesuai dengan kriteria metode webqual sebagai alat ukur agar tercapainnya kepuasan bagi Pengguna.

Berdasarkan penjabaran diatas maka rumusan masalah adalah Bagaimana aspek kemudahan pengguna (usability) website SIKMB di BP Batam; Bagaimana aspek kualitas informasi (information quality) website SIKMB di BP Batam; Bagaimana aspek kualitas interaksi (interaction quality) di BP Batam; Bagaimana persentase aspek kemudahan pengguna (usability), kualitas informasi (informasi quality), dan kualitas interaksi (interaction quality) pada website SIKMB di BP Batam. Tujuan penelitian adalah Untuk mengetahiu aspek kemudahan pengguna (usability) website SIKMB di BP Batam; Untuk mengetahui aspek kualitas informasi (information quality) website SIKMB di BP Batam; Untuk mengetahiu aspek kualitas interaksi (interaction quality) di BP Batam; Untuk mengetahui persentase aspek kemudahan pengguna (usability), kualitas informasi (informasi quality), dan kualitas interaksi (interaction quality) pada website SIKMB di BP Batam.

\section{LANDASAN TEORI}

Webqual sudah mulai dikembangkan sejak tahun 1998 dan telah mengalami beberapa iterasi dalam penyusunan dimensi dan butir-butir pertanyaannya. Penelitian [3] yang menggunakan webqual 4.0 untuk mengukur kualitas website yang dikelola oleh Organization for Economic Cooperation and Development (OECD). Webqual 4.0 tersebut disusun berdasarkan penelitian pada tiga area yaitu : Pertama, kualitas informasi dari penelitian sistem informasi. Kedua, interaksi dan kualitas layanan dari penelitian kualitas sistem informasi, e-commerce, dan pemasaran. Ketiga, usability dari human-computer interaction.

Webqual untuk menganalisis kualitas beberapa website, baik website internal (career center, staffsite, studentsite, central library, etc) maupun website eksternal (website maskapai penerbangan dan e-banking, etc). Persepsi Pengguna tersebut terdiri dari dua bagian, yaitu persepsi tentang mutu layanan yang dirasakan (aktual) dengan tingkat harapan (ideal) [4].

Webqual disusun berdasarkan konsep house of quality yang merupakan dasar penyusunan serqual. Instrumen yang digunakan kedua model tersebut pada intinya merupakan pertanyaan-pertanyaan (kuisioner) yang harus diisi oleh Pengguna langsung (end user) dari web (webqual) atau jenis layanan lain (servqual). Pengukuran dengan instrumen kuisoner tersebut bersifat pengukuran langsung (data primer) yang bersifat perspektual measurement. Ada metode lain yang bisa digunakan, misalnya dengan menggunakan web statistic yang didisain khusus [3].

Metode terakhir ini bersifat actual usage yang biasanya digunakan lebih ke arah analisis model adopsinya. Webqual bisa digunakan untuk mengukur kualitas setiap website, baik yang hanya bersifat informasional maupun transaksional. Dengan webqual ini bisa diketahui atribut atau fitur website apa saja yang sudah baik atau yang masih memerlukan perbaikan. 
Metode webqual merupakan teknik pengukuran untuk menentukan kualitas website. Metode ini terdiri atas 3 tahapan dalam menentukan kualitas website yaitu information quality, usability dan service interaction quality. Ketiga tahapan tersebut dapat memberikan informasi yang akurat dan memberikan penilaian terhadap kelayakan website [5]. Pada dasarnya mengukur mutu sebuah web berdasarkan persepsi dari Pengguna atau pengunjung situs. Jadi pengukurannya menggunakan instrument penelitian atau kuesioner. Oleh karena itu website SIKMB ini perlu dilakukan analisis kelayakan untuk meningkatkan kualitas website tersebut baik dari usability, information quality, dan interaction quality [5].

Aplikasi SIKMB merupakan aplikasi pengajuan perijinan impor dan ekspor barang di kawasan Batam Free Zone Batam milik BP Batam yang dapat dilakukan secara online sehingga dapat tercipta efisiensi, kemudahan, kinerja yang profesional, transparan dan cepat. Aplikasi ini digunakan oleh pihak pengusaha dalam proses pengajuan permohonan ijin usaha impor, pengakuan sebagai Importir Produsen atau Importir Terdaftar (Ijin IP atau Ijin IT) dan persetujuan pemasukan barang di Kawasan Perdagangan Bebas dan Pelabuhan Bebas Batam [1].

BP Batam akan melakukan sosialisasi dalam rangka pengunaan aplikasi online perizinan impor yang baru. Sosialisasi ini dilakukan karena adanya beberapa perubahan pada sistem aplikasi online SIKMB versi 2 yang baru serta untuk menupgrade pengetahuan pemohon dalam rangka Penggunaan aplikasi ini. Berdasarkan dari pengalaman sebelumnya, banyak perusahaan yang mendelegasikan pengurusan perizinan kepada staf yang baru sehingga perlu adanya pelatihan secara berkala bagi para pemohon dokumen. Aplikasi SIKMB versi terbaru akan mengakomodir semua jenis perizinan impor dan pelatihan direncanakan pertengahan bulan akhir Agustus 2013. Aplikasi SIKMB versi 2 merupakan aplikasi untuk, online untuk keluar masuk barang dimana pada versi 2 semua perizinan berkaitan dengan keluar masuk barang sudah di akomodir dalam modul aplikasi SIKMB versi 2. Diharapkan pengusaha agar menggunakan SIKMB versi 2 tanpa melalui perantara, sehingga perusahaan dapat benar-benar melakukan proses perizinan di kantor mereka masing-masing, karena sistem di buat berbasiskan web [1].

Sistem Informasi SIKMB adalah suatu sistem di dalam suatu organisasi yang mempertemukan kebutuhan pengolahan transaksi harian yang mendukung fungsi organisasi yang bersifat manajerial dalam kegiatan strategi dari suatu organisasi untuk dapat menyediakan kepada pihak luar tertentu dengan laporan-laporan yang diperlukan.

Impor barang ke dalam Kawasan Perdagangan Bebas dan Pelabuhan Bebas (KPB-PBB) atau FTZ Batam dapat dilakukan oleh pengusaha setelah mendapat ijin usaha impor oleh Badan Pengusahaan Kawasan Batam sesuai dengan Peraturan Pemerintah 02 tahun 2009. Setelah pengusaha atau importir mendapatkan ijin usaha impor dari BP Batam, harus memeriksa kembali barang yang akan di impor apakah termasuk dalam katagori bebas dari ketentuan Lartas, katagori terkena ketentuan lartas untuk barang yang dilarang atau katagori yang terkena ketentuan Lartas untuk barang yang dibatasi. Pemeriksaan barang apakah terkena Lartas atau tidak dapat dilakukan secara online dengan memasukan HS CODE barang yang akan 
di periksa oleh sistem, dan cara pemeriksaan HSCODE dapat dilihat pada menu penjelasan "E - Perijinan Lalu Lintas Barang - BP Batam". [1]

Dari hasil pemeriksaan barang, maka dapat digolongkan menjadi 3 katagori barang sebagai berikut [1]:

a. Kategori barang bebas : Barang yang tidak terkena ketentuan Lartas dan barang tidak bisa langsung di ajukan "Persetujuan Pemasukan Barang" ke BP Batam.

b. Kategori barang dibatasi : Barang yang terkena ketentuan Lartas untuk barang yang di batasi, pengusaha atau importir harus melengkapi dokumen impor dengan Ijin Importir Produsen (IP) atau Ijin Importir Terdaftar (IT) sesuai dengan komoditi barangnya. Ijin IP atau IT dapat diperoleh di BP Batam untuk perijinan yang sudah dilimpahkan oleh Kementrian Perdagangan. Sedangkan untuk ijin IP atau IT yang belum dilimpahkan, pengurusannya dilakukan di Kementrian Perdagangan. List IP dan IT yang dilimpahkan dan yang belum dilimpahkan dapat di lihat pada lampiran satu. Setelah mendapatkan ijin IP atau IT, maka dapat diajukan persetujuan Impor Barang ke BP Batam.

c. Kategori barang dilarang : Barang yang terkena ketentuan Lartas untuk barang yang dilarang untuk di impor ke kawasan FTZ Batam atau daerah Pabean Indonesia. Dokumen yang dikeluarkan oleh BP Batam dan merupakan persyaratan impor ke dalam kawasan FTZ Batam adalah:

1) Dokumen izin usaha impor

2) Dokumen pengakuan sebagai importir produsen atau importir terdaftar atau izin IP atau izin IT.

3) Dokumen persetujuan pemasukan barang.

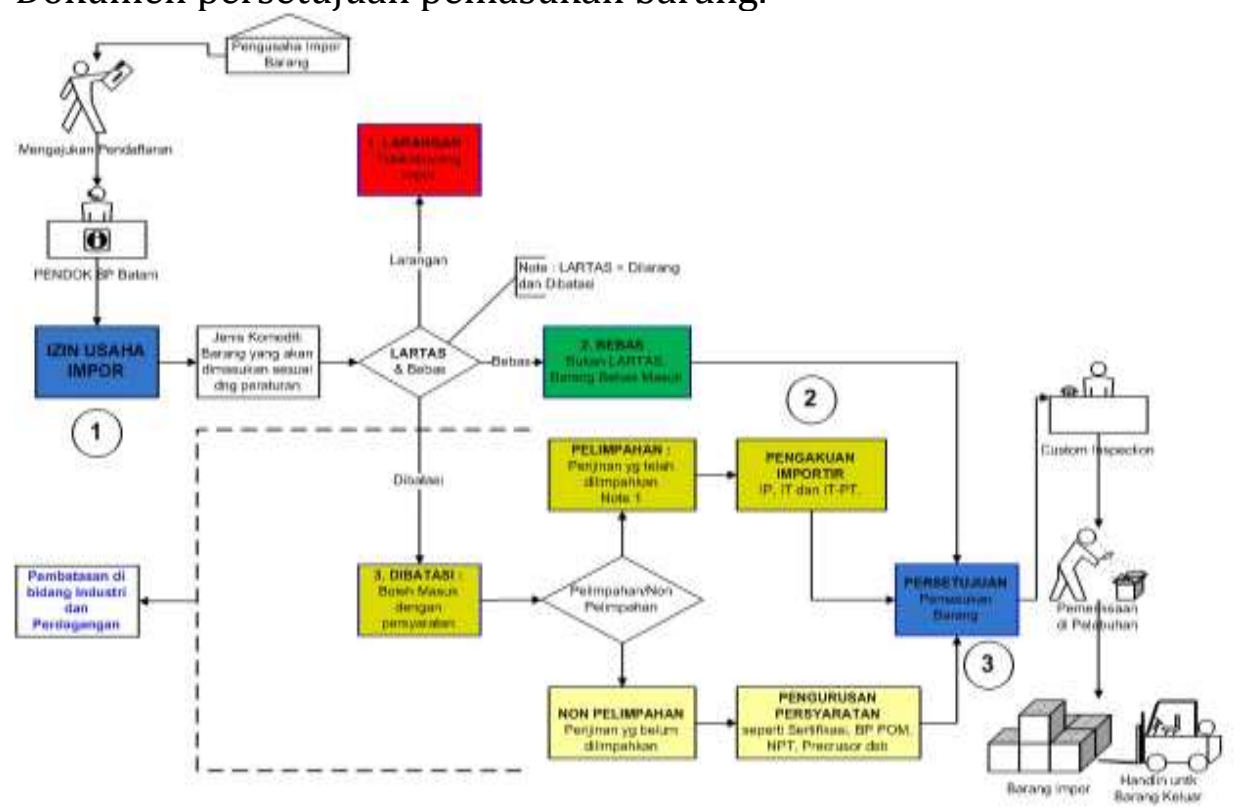

Gambar 1. Impor Ke Kawasan Perdagangan Bebas Batam

Sumber: [1]

Melakukan perancangan terhadap situs web adalah penting untuk memastikan bahwa informasi yang didapat benar dan berasal dari sumber yang terpercaya. Jika informasi yang digunakan tidak benar, maka informasi yang diolah 
dan disajikan tidak benar juga maka itu akan membawa kepada masalah penyebaran informasi yang salah [2].

Kualitas web akan sangat berpengaruh terhadap tingkat kepuasan Pengguna. Pada dasarnya tercapainya kualitas website yang sempurna akan mendorong terciptanya kepuasan, karena kualitas website merupakan sarana untuk mewujudkan kepuasan Pengguna dalam akses ke dalam situs web. Kualitas website tentu dapat diwujudkan dengan menampilkan website yang sesuai dengan kriteria metode webqual sebagai alat ukur agar tercapainya kepuasan bagi Pengguna [6].

Dalam webqual 4.0 dimensi kegunaan menarik dari literatur di bidang interaksi manusia komputer dan web lebih belakangan kegunaan [3]. Usability berkaitan dengan pragmatik tentang bagaimana Pengguna merasakan dan berinteraksi dengan situs web apakah mudah dinavigasi, apakah desain yang sesuai dengan jenis situs. Tidak, dalam contoh pertama, yang bersangkutan dengan prinsip-prinsip desain seperti Penggunaan frame atau persentase ruang putih, meskipun ini kekhawatiran bagi para desainer situs web yang dituduh meningkatkan kegunaan [7]. Pengukuran dengan metode webqual 4.0 disusun berdasarkan yaitu:

a. Kemudahan Penggunaan (usability) adalah suatu atribut kualitas yang menjelaskan atau mengukur seberapa mudah Penggunaan suatu antar muka (interface). Usability juga mengacu kepada metode untuk meningkatkan kemudahan Penggunaan selama proses perancangan. Adapun aspek kemudahan Penggunaan situs web (usability), dapat diketahui pada tabel di bawah ini:

Tabel 1. Aspek Kemudahan Penggunaan (Usability)

\begin{tabular}{cl}
\hline No. & \multicolumn{1}{c}{ Deskripsi Indikator } \\
\hline 1 & $\begin{array}{l}\text { Pengguna merasa mudah untuk mempelajari dan mengoperasi } \\
\text { Website }\end{array}$ \\
2 & $\begin{array}{l}\text { Interaksi antara Website dengan Pengguna jelas dan mudah } \\
\text { dipahami }\end{array}$ \\
3 & Pengguna merasa mudah Website untuk dinavigasikan \\
4 & Pengguna merasa mudah Webdite mudah digunakan \\
5 & Website memiliki tampilan yang menarik \\
6 & Desain sesuai dengan jenis Website \\
7 & Website mengandung kompetensi \\
8 & Website menciptakan pengalaman positif bagi Pengguna \\
\hline
\end{tabular}
Sumber: [8]

b. Kualitas informasi (information quality). Pada dasarnya tergantung dari tiga hal, yaitu informasi harus akurat (accurate), tepat pada waktunya (timely liness), dan relevan (relevancy). Adapun aspek kualitas informasi (information quality) tersebut, dapat diketahui pada tabel berikut: 
Tabel 2. Aspek Kualitas Informasi (Information Quality)

\begin{tabular}{cl}
\hline No. & \multicolumn{1}{c}{ Deskripsi Indikator } \\
\hline 1 & Menyediakan informasi yang akurat \\
2 & Menyediakan informasi yang dapat dipercaya \\
3 & Menyediakan informasi yang tepat waktu \\
4 & Menyediakan informasi yang relevan \\
5 & Menyediakan informasi yang mudah di mengerti \\
6 & Menyediakan informasi dengan detail yang sesuai \\
7 & Menampilkan informasi dengan format yang sesuai \\
\hline
\end{tabular}

Sumber: [8]

c. Kualitas interaksi (interaction quality) adalah mutu dari interaksi pelayanan yang dialami oleh Pengguna ketika mereka menyelidiki kedalam site lebih dalam, yang terwujud dengan kepercayaan dan empati, sebagai contoh isu dari keamanan transaksi dan informasi, pengantaran produk, personalisasi dan komunikasi dengan pemilik site.

Tabel 3. Aspek Kualitas Interaksi (Interaction Quality)

\begin{tabular}{cl}
\hline No. & \multicolumn{1}{c}{ Deskripsi Indikator } \\
\hline 1 & Website memiliki reputasi yang baik \\
2 & Pengguna merasa aman untuk melakukan transaksi \\
3 & Pengguna merasa aman terhadap informasi pribadinya \\
4 & Website memberi ruang untuk personalisasi \\
5 & Website memberikan ruang untuk komunitas \\
6 & Website memberikan kemudahan untuk berkomunikasi dengan \\
& organisasi \\
7 & Pengguna merasa yakin bahwa barang atau jasa akan dikirim \\
& sebagaimana yang telah dijanjikan \\
\hline
\end{tabular}

Sumber: [8]

Webqual dapat digunakan untuk menganalisis kualitas beberapa website, baik website internal perusahaan (intranet) maupun website eksternal. Persepsi Pengguna tersebut terdiri dari dua bagian, yaitu persepsi tentang mutu layanan yang dirasakan (actual) dengan tingkat harapan (ideal) [3] melakukan penelitian menggunakan webqual untuk mengukur kualitas website yang dikelola oleh Organization For Economic Cooperation and Development (OFECD).

Website yang bermutu dari perspektif Pengguna dapat dilihat dari tingkat persepsi layanan aktual yang tinggi dan kesenjangan persepsi aktual dengan ideal (gap) yang rendah. Model kualitas website atau webqual tersebut pertama kali digunakan pada portal sekolah bisnis berdasarkan faktor-faktor kemudahan Penggunaan, pengalaman, informasi dan komunikasi serta integrasi [6].

Berdasarkan kajian teori di atas, kerangka berpikir dalam penelitian ini yang berjudul Analisis Kualitas Layanan Website SIKMB Menggunakan Metode WebQual 4.0 (Studi Pada BP Batam). Untuk mempermudah dalam penelitian, peneliti menyusun bagan alur kerangka pemikiran sebagai berikut: 


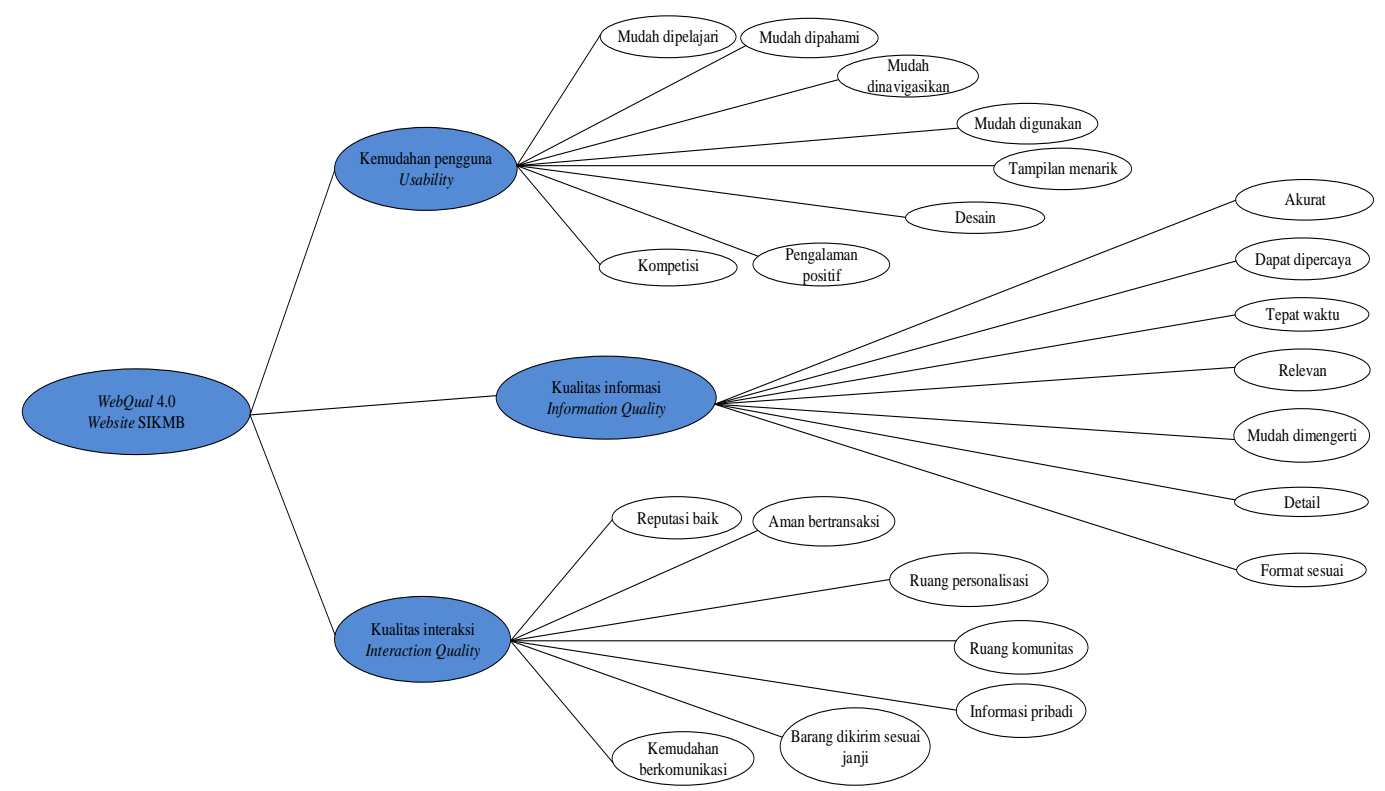

Gambar 2. Kerangka berfikir penelitian

Dari kerangka berfikir maka Hipotesisnya adalah H1 : Aspek kemudahan Penggunaan (usability) pada website SIKMB di BP Batam di persepsikan sudah baik; H2 : Aspek kualitas informasi (information quality) pada website SIKMB di BP Batam di persepsikan sudah baik; H3 : Aspek kualitas interaksi (interaction quality) pada website SIKMB di BP Batam di persepsikan sudah baik; H4 : Aspek kemudahan Pengguna (usability), kualitas informasi (informasi quality), dan kualitas interaksi (interaction quality) pada website SIKMB di BP Batam di persepsikan memiliki persentase yang baik.

\section{METODOLOGI PENELITIAN}

Metode penelitian ini menggunakan metode deskriptif [9]. Populasi dalam penelitian ini adalah website SIKMB dengan observasi penelitian pada Pengguna website SIKMB. Populasi pada penelitian ini adalah 151 Pengguna. Berdasarkan teknik pengambilan sampel di atas dengan menggunakan teknik sampling jenuh dari jumlah populasi sebanyak 151 orang, maka yang diambil sebagai sampel adalah sebanyak 151 orang. Objek Penelitian BP Batam. Data di peroleh dengan menggunakan kuesioner.

\section{HASIL DAN PEMBAHASAN}

\subsection{Analisis Deskriptif}

Statistik deskriftif menurut Sugiyono (2013: 147) mendefinisikan statistik deskriptif adalah statistik yang digunakan untuk menganalisis data dengan cara mendeskripsikan atau menggambarkan data yang telah terkumpul sebagaimana adanya tanpa bermaksud membuat kesimpulan yang berlaku umum atau generalisasi. Skor terendah diperoleh melalui hasil perhitungan bobot terendah dikalikan jumlah sampel, sedangkan skor tertinggi diperoleh melalui bobot tertinggi 
dikalikan jumlah sampel. Dalam mengukur hipotesis 1, 2, 3 penelitian ini, rumus yang digunakan untuk mengukur rentang skala adalah:

Keterangan:

$$
R K=\frac{n(m-1)}{m}
$$

$$
\begin{aligned}
& \mathrm{n}=\text { jumlah sampel } \\
& \mathrm{m}=\text { jumlah alternatif item }
\end{aligned}
$$
berikut:

Berdasarkan rumus tersebut maka diperoleh jumlah rentang skala sebagai

$$
R K=\frac{151(5-1)}{5} \quad R K=\frac{604}{5}=120.80
$$

Jadi kelas rentang skala pada penelitian ini adalah:

Tabel 4. Rentang Skala

\begin{tabular}{llll}
\hline No & Rentang Skala & & Kriteria \\
\hline 1 & $151.00-271.80$ & Sangat Tidak Baik & \\
2 & $271.81-392.61$ & Tidak Baik & \\
3 & $392.62-513.42$ & Cukup Baik & \\
4 & $513.43-634.23$ & Baik & \\
5 & $634.24-755.00$ & Sangat Baik & \\
\hline
\end{tabular}

Berdasarkan Tabel 4. diatas setiap satu rentang skala mewakili tiga variabel yaitu Kemudahan pengguna (Usability), Kualitas informasi (Information quality), Kualitas interaksi (Interaction quality).

\subsubsection{Kemudahan Penggunaan (Usability)}

\begin{tabular}{|c|c|c|c|c|c|c|c|c|}
\hline \multirow[t]{2}{*}{ No. } & \multirow{2}{*}{$\begin{array}{c}\text { Indikator Kemudahan } \\
\text { Penggunaan } \\
\text { (Usability) }\end{array}$} & \multicolumn{5}{|c|}{$\begin{array}{c}\text { Skala Likert (Data } \\
\text { Ordinal) }\end{array}$} & \multirow{2}{*}{$\begin{array}{c}\text { Total } \\
\text { Sampel }\end{array}$} & \multirow[t]{2}{*}{ Skor } \\
\hline & & 5 & 4 & 3 & 2 & 1 & & \\
\hline 1. & $\begin{array}{l}\text { Website SIKMB mudah } \\
\text { untuk dioperasikan. } \\
\text { Interaksi dengan Website }\end{array}$ & 36 & 105 & 7 & 3 & 0 & 151 & 627 \\
\hline 2. & $\begin{array}{l}\text { SIKMB jelas dan dapat di } \\
\text { mengerti. }\end{array}$ & 38 & 102 & 10 & 1 & 0 & 151 & 630 \\
\hline 3. & $\begin{array}{l}\text { Website SIKMB mudah } \\
\text { untuk navigasi. }\end{array}$ & 55 & 91 & 4 & 1 & 0 & 151 & 653 \\
\hline 4. & $\begin{array}{l}\text { Website SIKMB mudah } \\
\text { digunakan. }\end{array}$ & 27 & 84 & 34 & 5 & 1 & 151 & 584 \\
\hline 5. & $\begin{array}{l}\text { Tampilan Website SIKMB } \\
\text { yang atraktif. }\end{array}$ & 30 & 112 & 7 & 2 & 0 & 151 & 623 \\
\hline
\end{tabular}

Secara keseluruhan indikator Kemudahan Penggunaan (Usability) adalah seperti Tabel 5 di bawah ini:

Tabel 5. Indikator Variabel Kemudahan Penggunaan (Usability) 


\begin{tabular}{|c|c|c|c|c|c|c|c|c|}
\hline \multirow[t]{2}{*}{ No. } & \multirow{2}{*}{$\begin{array}{c}\text { Indikator Kemudahan } \\
\text { Penggunaan } \\
\text { (Usability) }\end{array}$} & \multicolumn{5}{|c|}{$\begin{array}{c}\text { Skala Likert (Data } \\
\text { Ordinal) }\end{array}$} & \multirow{2}{*}{$\begin{array}{c}\text { Total } \\
\text { Sampel }\end{array}$} & \multirow[t]{2}{*}{ Skor } \\
\hline & & 5 & 4 & 3 & 2 & 1 & & \\
\hline 6. & $\begin{array}{l}\text { Website SIKMB sudah } \\
\text { tepat dalam penyusunan } \\
\text { tata letak informasi. }\end{array}$ & 27 & 109 & 11 & 4 & 0 & 151 & 612 \\
\hline 7. & $\begin{array}{l}\text { Tampilan Website SIKMB } \\
\text { sudah sesuai dengan jenis } \\
\text { Website pemerintahan. }\end{array}$ & 42 & 91 & 17 & 0 & 1 & 151 & 626 \\
\hline 8. & $\begin{array}{l}\text { Adanya penambahan } \\
\text { pengetahuan dari } \\
\text { informasi Website SIKMB. }\end{array}$ & 34 & 111 & 5 & 1 & 0 & 151 & 631 \\
\hline & Skor Total & \multicolumn{4}{|c|}{4,986} & & \multirow{3}{*}{\multicolumn{2}{|c|}{$82.55 \%$}} \\
\hline & Skor Total Ideal & \multirow{2}{*}{\multicolumn{4}{|c|}{$\begin{array}{c}6,040 \\
623.25\end{array}$}} & & & \\
\hline & Skor Rata-Rata & & & & & & & \\
\hline
\end{tabular}

Berdasarkan Tabel 5 di atas, ternyata skor yang paling tinggi adalah website SIKMB mudah untuk navigasi dengan skor 653, sedangkan skor terendah adalah website SIKMB mudah digunakan dengan skor 584. Pada Tabel 5 di atas, terlihat bahwa Kemudahan Penggunaan (Usability) menghasilkan skor rata-rata 623.25. Apabila melihat Tabel rentang skala ternyata Kemudahan Penggunaan (Usability) ini termasuk pada range 513.43 - 634.23 (Tabel 4 pada rentang skala), sehingga Usability (Kemudahan Penggunaan) pada website SIKMB sudah baik dirasakan oleh Pengguna.

\subsubsection{Kualitas Informasi (Information Quality)}

Secara keseluruhan indikator Kualitas Informasi (Information Quality) adalah seperti Tabel 6 di bawah ini:

Tabel 6. Indikator Variabel Kualitas Informasi (Information Quality)

\begin{tabular}{|c|c|c|c|c|c|c|c|c|}
\hline \multirow[t]{2}{*}{ No. } & \multirow{2}{*}{$\begin{array}{c}\text { Indikator Kualitas } \\
\text { Informasi } \\
\text { (Information Quality) }\end{array}$} & \multicolumn{5}{|c|}{$\begin{array}{c}\text { Skala Likert (Data } \\
\text { Ordinal) }\end{array}$} & \multirow{2}{*}{$\begin{array}{l}\text { Total } \\
\text { Sampel }\end{array}$} & \multirow[t]{2}{*}{ Skor } \\
\hline & & 5 & 4 & 3 & 2 & 1 & & \\
\hline 1. & $\begin{array}{l}\text { Website SIKMB } \\
\text { menyediakan informasi } \\
\text { yang cukup jelas. } \\
\text { Website SIKMB }\end{array}$ & 17 & 114 & 14 & 6 & 0 & 151 & 595 \\
\hline 2. & $\begin{array}{l}\text { menyediakan informasi } \\
\text { yang dapat dipercaya. } \\
\text { Website SIKMB }\end{array}$ & 26 & 106 & 14 & 5 & 0 & 151 & 606 \\
\hline 3. & $\begin{array}{l}\text { menyediakan informasi } \\
\text { yang up to date }\end{array}$ & 56 & 85 & 9 & 1 & 0 & 151 & 649 \\
\hline 4. & $\begin{array}{l}\text { Website SIKMB } \\
\text { menyediakan informasi } \\
\text { yang relevan. }\end{array}$ & 27 & 115 & 5 & 4 & 0 & 151 & 618 \\
\hline 5. & $\begin{array}{l}\text { Website SIKMB } \\
\text { menyediakan informasi }\end{array}$ & 53 & 83 & 14 & 1 & 0 & 151 & 641 \\
\hline
\end{tabular}




\begin{tabular}{|c|c|c|c|c|c|c|c|c|}
\hline \multirow[t]{2}{*}{ No. } & \multirow{2}{*}{$\begin{array}{c}\text { Indikator Kualitas } \\
\text { Informasi } \\
\text { (Information Quality) }\end{array}$} & \multicolumn{5}{|c|}{$\begin{array}{c}\text { Skala Likert (Data } \\
\text { Ordinal) }\end{array}$} & \multirow{2}{*}{$\begin{array}{c}\text { Total } \\
\text { Sampel }\end{array}$} & \multirow[t]{2}{*}{ Skor } \\
\hline & & 5 & 4 & 3 & 2 & 1 & & \\
\hline 6. & $\begin{array}{l}\text { yang mudah dibaca dan } \\
\text { dipahami. } \\
\text { Website SIKMB } \\
\text { menyediakan informasi } \\
\text { yang cukup detail. } \\
\text { Website SIKMB }\end{array}$ & 49 & 85 & 16 & 1 & 0 & 151 & 635 \\
\hline 7. & $\begin{array}{l}\text { menyajikan informasi } \\
\text { dalam format yang sesuai. } \\
\text { Skor Total }\end{array}$ & 47 & 83 & 19 & 2 & 0 & 151 & 628 \\
\hline & $\begin{array}{l}\text { Skor Total Ideal } \\
\text { Skor Rata-Rata }\end{array}$ & & & $\begin{array}{l}285 \\
4.57\end{array}$ & & & 82.7 & \\
\hline
\end{tabular}

Berdasarkan Tabel 6 di atas, ternyata skor yang paling tinggi adalah website SIKMB menyediakan informasi yang up to date dengan skor 649 sedangkan skor terendah adalah website SIKMB menyediakan informasi yang cukup jelas dengan skor 595. Pada Tabel 6 di atas, terlihat bahwa Kualitas Informasi (Information Quality) menghasilkan skor rata-rata 624.57. Apabila melihat Tabel rentang skala, ternyata bahwa Kualitas Informasi (Information Quality) ini termasuk pada range 513.43 - 634.23 (Tabel 4 pada rentang skala), sehingga Kualitas Informasi (Information Quality) pada website SIKMB sudah baik dirasakan oleh Pengguna.

\subsubsection{Kualitas Interaksi (Interaction Quality)}

Secara keseluruhan indikator Kualitas Interaksi (Interaction Quality) adalah seperti Tabel 7 di bawah ini:

Tabel 7. Indikator Variabel Kualitas Interaksi (Interaction Quality)

\begin{tabular}{|c|c|c|c|c|c|c|c|c|}
\hline \multirow{2}{*}{ No. } & \multirow{2}{*}{$\begin{array}{c}\text { Indikator Kualitas } \\
\text { Interaksi } \\
\text { (Interaction } \\
\text { Quality) } \\
\end{array}$} & \multicolumn{5}{|c|}{$\begin{array}{c}\text { Skala Likert (Data } \\
\text { Ordinal) }\end{array}$} & \multirow{2}{*}{$\begin{array}{c}\text { Total } \\
\text { Sampel }\end{array}$} & \multirow{2}{*}{ Skor } \\
\hline & & 5 & 4 & 3 & 2 & 1 & & \\
\hline 1. & $\begin{array}{l}\text { Website SIKMB } \\
\text { mempunyai reputasi } \\
\text { yang baik. }\end{array}$ & 47 & 80 & 21 & 3 & 0 & 151 & 624 \\
\hline 2. & $\begin{array}{l}\text { Pengguna } \\
\text { mendapatkan } \\
\text { keamanan untuk } \\
\text { melengkapi transaksi. }\end{array}$ & 47 & 78 & 19 & 5 & 2 & 151 & 616 \\
\hline 3. & $\begin{array}{l}\text { Pengguna merasa } \\
\text { aman dalam } \\
\text { menyampaikan data } \\
\text { pribadi. }\end{array}$ & 28 & 99 & 19 & 5 & 0 & 151 & 603 \\
\hline
\end{tabular}




\begin{tabular}{|c|c|c|c|c|c|c|c|c|}
\hline \multirow{2}{*}{ No. } & \multirow{2}{*}{$\begin{array}{c}\text { Indikator Kualitas } \\
\text { Interaksi } \\
\text { (Interaction } \\
\text { Quality) } \\
\end{array}$} & \multicolumn{5}{|c|}{$\begin{array}{c}\text { Skala Likert (Data } \\
\text { Ordinal) }\end{array}$} & \multirow{2}{*}{$\begin{array}{c}\text { Total } \\
\text { Sampel }\end{array}$} & \multirow{2}{*}{ Skor } \\
\hline & & 5 & 4 & 3 & 2 & 1 & & \\
\hline 4. & $\begin{array}{l}\text { Kemudahan Website } \\
\text { SIKMB untuk menarik } \\
\text { minat dan perhatian } \\
\text { Pengguna. }\end{array}$ & 23 & 108 & 18 & 2 & 0 & 151 & 605 \\
\hline 5. & $\begin{array}{l}\text { Adanya suasana } \\
\text { komunitas pada } \\
\text { Website SIKMB. }\end{array}$ & 35 & 99 & 17 & 0 & 0 & 151 & 622 \\
\hline 6. & $\begin{array}{l}\text { Kemudahan Pengguna } \\
\text { untuk memberi } \\
\text { masukan (feed back) } \\
\text { pada Website SIKMB. }\end{array}$ & 47 & 86 & 15 & 3 & 0 & 151 & 630 \\
\hline 7. & $\begin{array}{l}\text { Tingkat kepercayaan } \\
\text { yang tinggi atas } \\
\text { informasi yang } \\
\text { disampaikan Website } \\
\text { SIKMB. }\end{array}$ & 25 & 107 & 15 & 4 & 0 & 151 & 606 \\
\hline & Skor Total & \multicolumn{5}{|c|}{4,306} & \multirow{2}{*}{\multicolumn{2}{|c|}{$81.48 \%$}} \\
\hline & $\begin{array}{l}\text { Skor Total Ideal } \\
\text { Skor Rata-Rata }\end{array}$ & \multicolumn{5}{|c|}{$\begin{array}{c}5,285 \\
615.14\end{array}$} & & \\
\hline
\end{tabular}

Berdasarkan Tabel 7 di atas, ternyata skor yang paling tinggi adalah Kemudahan Pengguna untuk memberi masukan (feed back) pada website SIKMB dengan skor 630, sedangkan skor terendah adalah Pengguna merasa aman dalam menyampaikan data pribadi dengan skor 603. Pada Tabel 7 di atas, terlihat bahwa Kualitas Interaksi (Interaction Quality) menghasilkan skor rata-rata 615.14. Apabila melihat Tabel rentang skala, ternyata bahwa Kualitas Interaksi (Interaction Quality) ini termasuk pada range 513.43 - 634.23 (Tabel 4 pada rentang skala), sehingga Kualitas Interaksi (Interaction Quality) pada website SIKMB sudah baik dirasakan oleh Pengguna.

Tabel 8. Persentase Skor Variabel Kemudahan Pengguna (Usability), Kualitas Informasi (Informasi Quality), dan Kualitas Interaksi (Interaction Quality)

\begin{tabular}{lcc}
\hline \multicolumn{1}{c}{ Variabel } & Skor & Persentase \\
\hline Kemudahan Pengguna (Usability) & 623 & $82.55 \%$ \\
Kualitas Informasi (Informasi Quality) & 625 & $82.72 \%$ \\
Kualitas Interaksi (Interaction Quality) & 615 & $81.48 \%$ \\
Skor Rata Ketiga Variabel & 621 & $82.25 \%$ \\
\hline
\end{tabular}

Dari tabel 8 di atas hasil analisis deskriptif maka responden yang memberikan pernyataan tentang Kemudahan Pengguna (Usability) di dapat skor rata-rata 623 dengan persentase $82.55 \%$, memberikan pernyataan tentang Kualitas Informasi 
(Informasi Quality) di dapat skor rata-rata 625 dengan persentase 82.72\%, memberikan pernyataan tentang Kualitas Interaksi (Interaction Quality) di dapat skor rata-rata 615 dengan persentase $81.48 \%$.

Berdasarkan hasil di atas dari ketiga variabel Kemudahan Pengguna (Usability), Kualitas Informasi (Informasi Quality), dan Kualitas Interaksi (Interaction Quality), ternyata skor yang paling tinggi adalah Kualitas Informasi (Informasi Quality) dengan skor rata-rata 625 dengan persentase 82.72\%, sedangkan skor terendah adalah Kualitas Interaksi (Interaction Quality) dengan skor rata-rata 615 dengan persentase $81.48 \%$.

Pada Tabel 8 di atas, terlihat bahwa Kemudahan Pengguna (Usability), Kualitas Informasi (Informasi Quality), dan Kualitas Interaksi (Interaction Quality) menghasilkan skor rata-rata 621 dengan persentase $82.25 \%$. Apabila melihat Tabel 4 pada rentang skala, ternyata bahwa Kemudahan Pengguna (Usability), Kualitas Informasi (Informasi Quality), dan Kualitas Interaksi (Interaction Quality) ini termasuk pada range 513.43 - 634.23 (Tabel 4 pada rentang skala), sehingga Kemudahan Pengguna (Usability), Kualitas Informasi (Informasi Quality), dan Kualitas Interaksi (Interaction Quality) pada website SIKMB sudah baik dirasakan oleh Pengguna.

\section{SIMPULAN}

Peneliti mencoba membuat beberapa kesimpulan berdasarkan hasil penelitian dan pembahasan yang sudah dijelaskan sebelumnya, sebagai berikut:

a. Aspek Kemudahan Penggunaan (Usability) pada website SIKMB di BP Batam sudah baik.

b. Aspek Kualitas Informasi (Information Quality) pada website SIKMB di BP Batam sudah baik.

c. Aspek Kualitas Interaksi (Interaction Quality) pada website SIKMB di BP Batam sudah baik.

d. Namun keseluruhan nilai kualitas website SIKMB terhadap dimensi Kemudahan Pengguna (Usability), Kualitas Informasi (Informasi Quality), dan Kualitas Interaksi (Interaction Quality) pada website SIKMB di BP Batam berada dalam kualitas yang baik.

\section{DAFTAR PUSTAKA}

[1] http://sikmb.bpbatam.go.id/welcome/berita_det/11,[10 November 2015]

[2] Simamarta, Janner. "REKAYASA PERANGKAT LUNAK", Andi Offset, Yogyakarta. 2010.

[3] Barnes, S., and Vidgen, R. "DATA TRIANGULATION IN ACTION: USING COMMENT ANALYSIS TO REFINE WEB QUALITY METRICS”. In: Proceedings of the 13 th European Conference on Information Systems, Regensburg, Germany, May 26-28.

[4] Zahreza Fajar Setiara Putra, Mohammad Sholeh, dan Naniek Widyastuti. “ANALISIS KUALITAS LAYANAN WEBSITE BTKP-DIY MENGGUNAKAN 
METODE WEBQUAL 4.0", Jurnal JARKOM Vol. 1 No. 2 Januari 2014, ISSN:2338-6312.

[5] Miftah Nasution, Mudjahidin. “ANALISIS KUALITAS LAYANAN WEBSITE KANTOR PELAYANAN PERBENDAHARAAN NEGARA (KPPN) SURABAYA I DENGAN MENGGUNAKAN WEBQUAL", Jurnal Teknik Pomits Vol. 2, No. 1, (2013) ISSN: 2337-3539.

[6] Sanjaya, Iman. "PENGUKURAN KUALITAS LAYANAN WEBSITE KEMENTRIAN KOMINFO DENGAN MENGGUNAKAN METODE WEBQUAL 4.0", Jurnal Penelitian IPTEK-KOM, Volume 14, No. 1, Juni 2012.

[7] Yaghoubi, Nour Mohammad, Hamed Armesh, Ramin Azadavar, Hashem Nasrabadi and Hamid Khajooei, "INTERNET BOOKSTORE QUALITY ASSESSMENT: IRANIAN EVIDENCE", Journal of Business Management Vol. 5(30), pp. 12031-12039, 30 November, 2011 Available online at http://www.academicjournals.org/AJBM DOI: 10.5897/AJBM11.1152, ISSN 1993-8233.

[8] Siti Sa'uda, dan Nyimas Sopiah. "PENERAPAN METODE WEBQUAL DALAM PENGUKURAN KUALITAS LAYANAN WEBSITE PERGURUAN TINGGI", Prosiding SnaPP2014 Sains, Teknologi, dan Kesehatan ISSN 2089-3582, EISSN 2303-2480.

[9] Nazir, Moh. “METODE PENELITIAN", Penerbit Ghalia Indonesia, Jakarta. 2014. 